\title{
Crescimento e Adaptabilidade de Procedências e Progênies de Pinus tecunumanii no Norte de Moçambique
}

\author{
Growth and Adaptability of Provinences and family-within-provenance of Pinus \\ tecunumanii in Northern Mozambique
}

\author{
Cremildo Riba Gouveia Dias ${ }^{1,2 \star}$, Aires Afonso Mbanze ${ }^{3}$ \\ ${ }^{1}$ Instituto de Investigação Agraria de Moçambique, Lichinga, Niassa, Moçambique. *Autor para correspondência: \\ cremildodias23.rgd@gmail.com \\ ${ }^{2}$ Instituto Politécnico de Bragança, Escola Superior Agrária, Bragança, Portugal . \\ ${ }^{3}$ Universidade Lúrio, Faculdade de Ciências Agrárias, Unango, Niassa, Moçambique.
}

Submissão: 14/09/2019 / Aceite: 22/06/2020

\begin{abstract}
RESUMO
Empresas florestais necessitam maximizar lucros e minimizar o nível de risco e incerteza, sendo uma das principais estratégias plantar povoamentos de crescimento rápido e de alta produtividade. Foi com esse intuito que a Empresa Florestas do Niassa, estabeleceu um experimento com cinco procedências e 28 progênies de $P$. Tecunumanii Eguiluz \& Perry, no norte de Moçambique. O experimento foi estabelecido em blocos ao acaso com quatro linhas de repetição. Aos dois, quatro e oito anos de idade foram medidas altura total, diâmetro altura do peito (DAP) e sobrevivência. Os resultados de sobrevivência aos oito anos de idade não apresentaram diferenças significativas, tendo ficado acima dos $90 \%$ para todas as procedências incluindo a testemunha. Houve diferenças significativas de crescimento entre procedência para os restantes parâmetros avaliados. O melhor desempenho aos oito anos foi para as procedências Villa Santa, San Rafael del Norte e Yucul. O desdobramento das procedências entre progênies com o uso do recurso de agrupamento de clusters identificou três grupos distintos: O primeiro, composto pelas 12 $(41,38 \%)$ progênies de melhor desempenho, majoritariamente da Villa Santa e Yucul; o segundo intermediário e composto por sete (24,14\%) das progênies, na sua maioria de Yucul e Km 33; o último foi composto por 10 (34,4\%) das progênies de pior desempenho, na sua maioria de San Jeronimo e Km 33. A maior parte das 10 melhores progênies classificadas com base no efeito genético aditivo predito e ganho genético, pertencem a Villa Santa, confirmando os resultados dos clusters. Já a maioria das progênies (45\%) ao nível dos 20 melhores indivíduos classificados, pertenceram a procedência Villa Santa e podem ser usadas para futuros projetos de melhoramento no ambiente do Niassa. A seleção das melhores progênies pode ser feita a partir do DAP, dado que este apresentou um coeficiente de correlação acima dos $90 \%$ com o volume.
\end{abstract}

PALAVRAS-CHAVE: adaptabilidade, crescimento, ensaios de procedências e progênies e seleção fenotípica.

\begin{abstract}
The goal of company's forest is to maximize revenues, while minimizing risk and uncertainty. One key strategy to achieve this objective is planting fast-growing and high-yield forest stands. Thus, the Company Florestas do Niassa, operating in Niassa Province, established an experiment trial of five provenances and 28 family-within-provenances of $P$. Tecunumanii Eguiluz \& Perry in northern Mozambique. The experiment was established in Randomized Complete Blocks Design with four lines of replications. Total height, the Diameter at Breast Height $(\mathrm{DBH})$ and survival were assessed at two, four, and eight years. Survival was not significantly different at 8 years and it was above $90 \%$ for all provenances, including the control. There were significant growth differences between provenance for the rest of parameters evaluated. The proveniences that best performed at eight years, were Villa Santa, San Rafael del Norte and Yucul. Cluster method used to breakdown the provenances between progenies was useful to identified three distinct groups of progenies: The first, consisted to 12 (41.38\%) of the best performing progenies, mostly from Villa Santa and Yucul; the second which was intermediate was composed with seven (24.14\%) progenies mostly Yucul and $\mathrm{Km} 33$; The latter consisted of 10 (34.4\%) of the worse performing progenies, mostly San Jeronimo and $\mathrm{Km} \mathrm{33}$. Most of the top 10 progenies ranked on the basis of predicted additive genetic effect and genetic gain, belonged to the providence Villa Santa, which was in accordance to the previous clusters results. Most of the progenies (45\%) at the level of the 20 best classified individuals also belonged
\end{abstract}


to Villa Santa and can be used for future tree breeding programmes in the environment of Niassa. The selection of the best progenies can be done through $\mathrm{DBH}$, since it had a correlation coefficient above $90 \%$ with the volume.

KEYWORDS: adaptability, growth, precedencies and progenies trial, Pinus tecunumanii and phenotypic selection.

\section{INTRODUÇÃO}

O estabelecimento de povoamentos florestais com espécies exóticas de rápido crescimento em Moçambique, data do período colonial. Nesse período, os plantios eram em pequenas propriedades, e tinham como objetivo principal suprir as necessidades do mercado doméstico e paralelamente testar o crescimento e adaptabilidade de espécies e procedências nas condições locais (SHIMIZU 2006). Logo após a independência do país, em 1975, seguiu-se um período de rápido desenvolvimento de povoamentos exóticos, culminando com o estabelecimento dos projetos FO1 e FO2, no sul e centro de Moçambique, sendo a maior parte com as espécies, Eucalyptus saligna, Eucalyptus grandis, Pinus patula e Casuarina equisetifolia, que foram abandonados no auge da guerra civil dos 16 anos, entre 1977 e 1992, (MINISTÉRIO DA AGRICULTURA 2006).

Após o final da guerra civil, houve necessidade de atrair novos investimentos para plantações com espécies exóticas de rápido crescimento, com o objetivo de: i) recuperar as terras improdutivas abandonadas devido a agricultura itinerante (INDE 2009); ii) criar postos de trabalho e, iii) reduzir a pressão sobre as florestas nativas devido ao crescimento populacional (LANDRY \& CHIRWA 2011, NUBE et al. 2016, ZANELLA et al. 2018). Sendo a província do Niassa a que atraiu a maior parte dos investimentos, devido a disponibilidade de terras, consequência da baixa densidade populacional.

Desde o ano 2000, só na Província do Niassa, mais de um milhão de hectares de terras foram alocados para estabelecimento de empresas agrícolas e florestais (SEUFERT 2012), das quais até 2010 operavam seis empresas florestais (MBANZE et al. 2013), com aproximadamente 30.000 hectares de terras plantadas (OVERBEEK 2010). As principais espécies usadas para o estabelecimento desses plantios eram, Eucalyptus grandis, Pinus elliottii, $P$. Patula e $P$. taeda, que já existiam nos povoamentos datados do tempo colonial. Mais tarde, foram também introduzidas, $P$. tecunumanii, $P$. maximinoi e P. Oocarpa, com recomendação da Central America and Mexico Coniferous Resources Cooperative (CAMCORE). Porém, devido ao déficit de informação sobre adaptabilidade, crescimento e produção de espécies exóticas no ambiente de Niassa, a maior parte das empresas estabeleciam plantios e experimentos simultaneamente e que abrangiam desde técnicas silviculturais (INVUA 2014) até melhoramento florestal de várias espécies de Eucalyptus e de Pinus (ensaios de espécies e procedências) (NHANTUMBO 2014).

Pinus tecunumanii é globalmente reconhecida como uma das espécies mais importantes no estabelecimento de plantações comerciais de rápido crescimento (VAN ZONNEVELD et al. 2009, ZANELLA et al. 2018). A espécie tem mostrado um bom desempenho em outras zonas introduzidas na América Latina e África (DVORAK et al. 1993, KARIUKI 1998, CARPENTER et al. 2004), e possui potencial para substituir espécies exóticas tradicionalmente plantadas no norte de Moçambique (MUNTHALI \& STEWAR 1998, HONGWANE et al. 2017), mas pouco ou nada se sabe sobre o seu desempenho nesse país. A introdução desta espécie na província de Niassa em Moçambique foi feita sem nenhum ensaio preliminar de adaptabilidade, embora grande parte da literatura aponta existir compatibilidade entre o local de origem da espécie com as condições edafoclimáticas de Niassa ( EGUILUZ-PIEDRA \& PERRY 1983, AGUIAR et al. 2011, CERDA-GRANADOS \& DÍAZ 2013). No entanto, para maximizar o crescimento e produção da mesma, é preciso identificar procedências e progênies que melhor se adaptam ao ambiente do norte de Moçambique, em função dos diferentes tratamentos culturais e procedimentos silviculturais. É nesse contexto que a Empresa Florestas de Niassa Limitada ( $F d N)$, com o auxílio da CAMCORE estabeleceram sete experimentos de Pinus tropicais (LÓPEZ 2014), sendo um desses ensaios o objeto do presente estudo, que visa avaliar o crescimento e adaptabilidade de procedências e progênies de $P$. tecunumanii Eguiluz \& Perry no ambiente de Chimbonila em Moçambique. As seguintes questões de pesquisa foram levantadas para melhor delinear as fronteiras de atuação do presente estudo: i) será que $P$. tecunumanii possui potencial de crescimento e adaptabilidade superior as espécies tradicionalmente plantadas no norte de Moçambique? ii) quais proveniências e procedências podem ser selecionadas para plantação intensiva e os futuros programas de melhoramento florestal no norte de Moçambique? Essas questões foram respondidas a partir da avaliação de resultados aos dois, quatro e oito anos de idade de um ensaio de $P$. tecunumanii, Rev. Ciênc. Agrovet., Lages, SC, Brasil (ISSN 2238-1171) 
estabelecido nos campos de ensaio da empresa Florestas do Niassa.

\section{MATERIAL E MÉTODOS}

\section{Localização da área de Estudo}

O experimento foi estabelecido pela Empresa Floresta de Niassa Lda, na localidade de Mussa, Distrito de Chimbonila, Província de Niassa, nas coordenadas $13^{\circ} 14$ '15,8" Lat Sul e $35^{\circ} 30^{\prime} 45,2^{\prime \prime}$ Long Leste, numa altitude de 1181 metros (Figura 1). O clima da região é temperado húmido (Cwb), com duas estações do ano bem definidas: Verões temperados e chuvosos e invernos secos e frios. A temperatura média anual é de $21{ }^{\circ} \mathrm{C}$, sendo que a precipitação total anual é de $1200 \mathrm{~mm}$ (MAE 2014). Os solos da região são majoritariamente argilosos, vermelhos profundos e com baixa susceptibilidade à ocorrência de erosão (SHIMANIKIRE 2011).

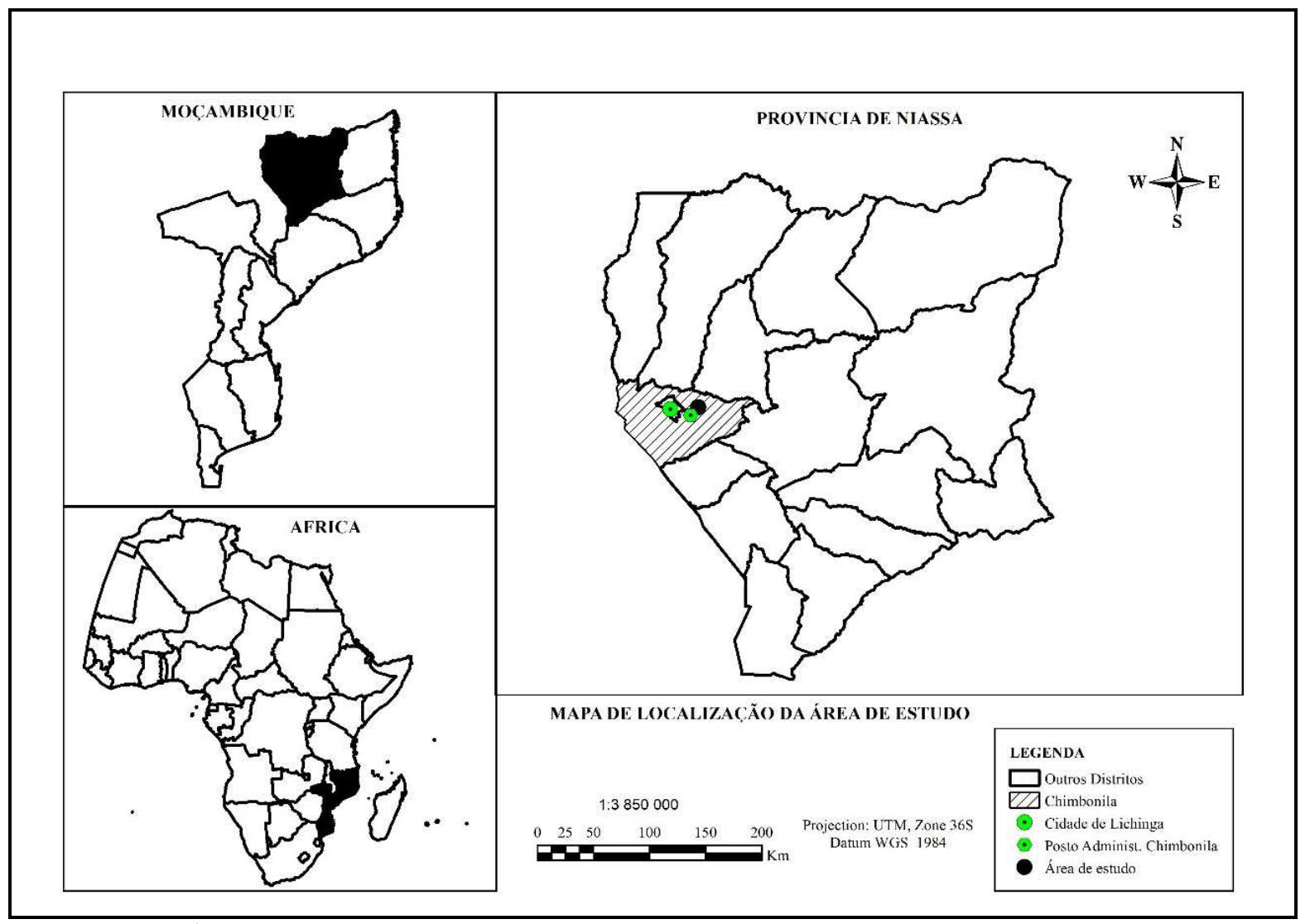

Fonte: O Autor ${ }^{1}$ (2019).

Figura 1. Localização geográfica da área de estudo.

Figure 1. Geographical location of the study area.

\section{Estabelecimento do ensaio}

O ensaio foi estabelecido em blocos ao acaso, numa área de 0,65 ha, tendo as seis procedências como parcelas principais e 29 progênies nas subparcelas em linhas de seis plantas, num espaçamento de $3 \mathrm{~m} \times 3 \mathrm{~m}$ e com duas linhas de bordadura $\mathrm{cm}$ (ver Anexo 1). Não houve preparo do solo, apenas 0 coveamento manual com uma profundidade de $35 \mathrm{~cm}$ para o plantio das mudas. Na época de plantio, as mudas tinham quatro meses e uma altura média de $22,5 \mathrm{~cm}$. O estabelecimento ocorreu no mês de janeiro de 2011 e seguiu as recomendações da CAMCORE, que também forneceu as sementes. Os detalhes relativos as condições da zona de origem das proveniências estão na Tabela 1. Enquanto na Figura 2 são apresentadas duas fotos do ensaio.

$\mathrm{Na}$ ocasião do plantio foi aplicado hidrogel no sistema radicial das mudas, através da imersão em uma solução na concentração de $10 \mathrm{~g} /$ /itro. A adubação de cobertura foi efetuada 30 dias após o plantio, com a aplicação de $100 \mathrm{~g}$ de NPK (17,38 \% - 28,51 \% - $4 \%$,) e adição 5\% de enxofre, 0,8\% de zinco e 0,5\% de boro por cova. Essas dosagens foram determinadas em função das análises de amostras de solo feitas anteriormente. Não foi feita nenhuma adubação de base. O primeiro desrame foi feito aos quatro anos de idade, com uma intensidade de $30 \%$ da altura total da copa, quando a altura média das plantas era de Rev. Ciênc. Agrovet., Lages, SC, Brasil (ISSN 2238-1171) 
aproximadamente $6 \mathrm{~m}$. O segundo desrame fez-se aos seis anos de idade com uma intensidade de $50 \%$ da altura total da copa, quando o povoamento tinha uma altura média de aproximadamente $10 \mathrm{~m}$. Também era feita limpeza total (capina) uma vez por ano, nos primeiros quatro anos após o plantio.

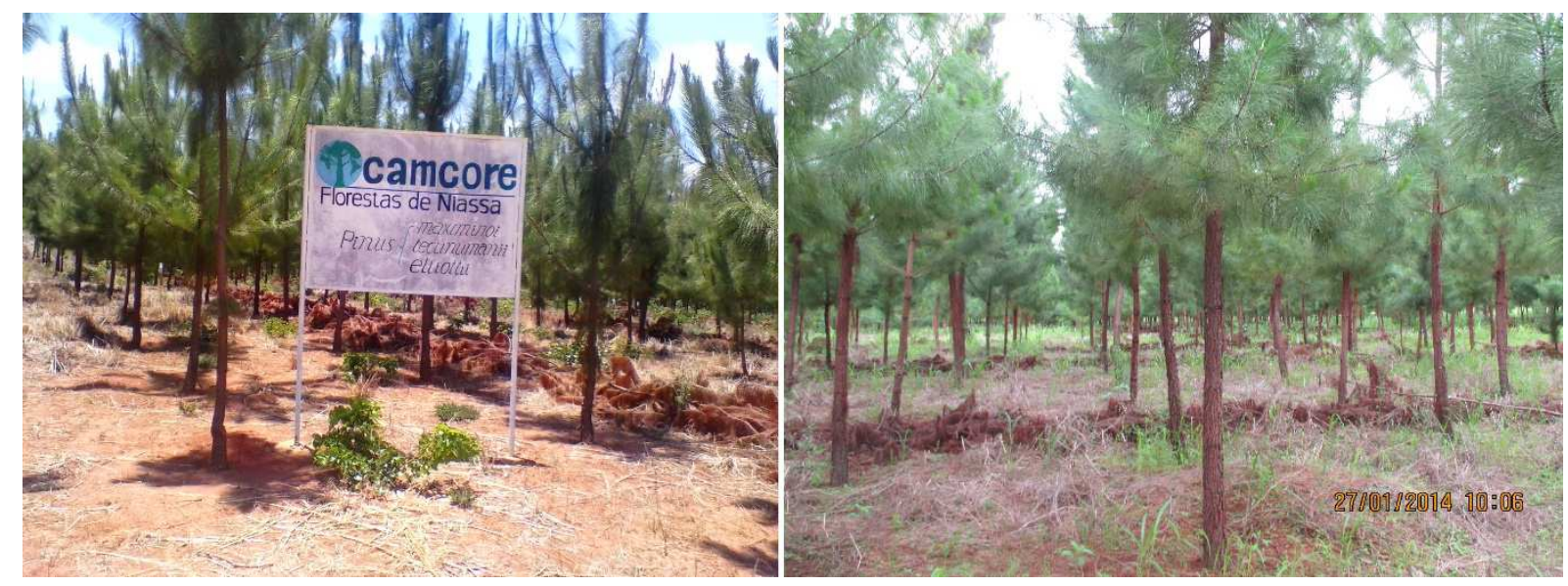

Figura 2. Campo de ensaio de P. tecunumanii estabelecido na empresa Florestas do Niassa, Localidade de Mussa. Foto tirada aos 4 anos de idade, a esquerda placa da Camcore com os três ensaios estabelecidos incluindo o do $P$. tecunumanii avaliado neste estudo.

Figure 2. Field trial of $P$. Tecunumanii established in the company Florestas do Niassa, Mussa locality. Photo taken at the age of 4 , on the left is the Camcore plaque of three experiments described including the one of $P$. Tecunumanii evaluated in this study.

Tabela 1. Procedências, progênies e caracterização edafoclimática dos locais de origem das procedências utilizadas no experimento com Pinus tecunumanii em Mussa, Província de Niassa, Moçambique.

Table 1. Provenances, progenies and soil and climatic characterization of the origins source locations used in the experiment with Pinus tecunumanii in Mussa, Niassa Province, Mozambique.

\begin{tabular}{|c|c|c|c|c|c|c|c|c|}
\hline $\begin{array}{l}\text { Procedências } \\
\text { (Abreviação) }\end{array}$ & País & $\begin{array}{c}\text { Estado/ } \\
\text { Província }\end{array}$ & $\begin{array}{c}\text { № de } \\
\text { progênies }\end{array}$ & Latitude & Longitude & $\begin{array}{l}\text { Elevação } \\
(\mathrm{m})\end{array}$ & $\begin{array}{c}\text { Precipitação } \\
(\mathrm{mm})\end{array}$ & $\begin{array}{c}\text { Temp. } \\
\text { média anual } \\
\left({ }^{\circ} \mathrm{C}\right)\end{array}$ \\
\hline $\mathrm{Km} 33(\mathrm{Km})$ & Guatemale & Guatemala & 6 & $14 \div 32^{\prime} \mathrm{N}$ & $90^{\circ} 19^{\prime} \mathrm{W}$ & $2000-2200$ & 1543 & $-\overline{---}$ \\
\hline Villa Santa (VS) & Honduras & El Paraiso & 7 & $14^{\circ} 12^{\prime} \mathrm{N}$ & $86^{\circ 17^{\prime} \mathrm{W}}$ & $800-1000$ & 1302 & 22,9 \\
\hline $\begin{array}{l}\text { San Jerónimo } \\
\text { (SJ) }\end{array}$ & Guatemal & $\begin{array}{l}\text { Baja } \\
\text { Verapaz }\end{array}$ & 6 & $15^{\circ} 00^{\prime} \mathrm{N}$ & $90^{\circ} 15^{\prime} \mathrm{W}$ & $1620-1850$ & 1200 & 21,9 \\
\hline Yucul (YI) & Nicarágua & Matagalpa & 7 & $12^{\circ} 55^{\prime} \mathrm{N}$ & $85^{\circ} 47^{\prime} \mathrm{W}$ & $900-1100$ & 1394 & 22,4 \\
\hline $\begin{array}{l}\text { San Rafael del } \\
\text { Norte (SRN) }\end{array}$ & Nicarágua & Jinotega & 2 & $13^{\circ} 14^{\prime} \mathrm{N}$ & $86^{\circ} 07^{\prime} \mathrm{W}$ & $920-1040$ & 1394 & 18 \\
\hline Controle & Zimbabwe & ----------- & ------ & -------- & -------- & -------- & ------ & ----- \\
\hline
\end{tabular}

Fonte: DOVORAK et al. 2000.

\section{Coleta de dados}

Os parâmetros medidos no campo foram altura total $(\mathrm{HT})$ em metros aos dois, quatro e oito anos de idade e diâmetro à altura do peito (DAP), apenas aos quatro e oito anos de idade. A medição das alturas foi realizada com uso do hipsômetro "Vertex IV" e uma vara graduada com $10 \mathrm{~cm}$ de precisão, quando necessário. O DAP das árvores foi medido com auxílio de uma Suta de alumínio. Foi também avaliada sobrevivência a partir da contagem de árvores vivas no segundo e oitavo ano.

\section{Análise de dados}

O nível de sobrevivência das procedências foi expresso em percentagem. A estimativa do volume total com casca de árvores individuais no quarto e oitavo ano, foi feita utilizando-se a Fórmula 1, para Pinus sp., em idade juvenil que é bastante utilizada para Pinus tecunumanii, ver por exemplo LADRACH (1986), MUNTHALI \& STEWAR (1998), HODGE \& DVORAK (1999) e GAPARE et al. (2001).

$$
\mathrm{Vol}=0,0003 \times \mathrm{DAP}^{2} \times \mathrm{HT}
$$


Onde: Vol é o volume é expresso em metros cúbicos, o DAP é o Diâmetro a Altura do Peito em centímetros e HT é altura total em metros.

A seleção dos melhores indivíduos foi feita de forma hierárquica, a partir das procedências, progênies até ao nível mais baixo dos 20 melhores indivíduos, conforme a metodologia detalhada que se segue:

i) Foi feita análise de variância (ANOVA) ao nível das procedências e posteriormente ao nível de progênies dentro de cada procedência, para captar melhor a variabilidade entre progênies e assim, identificar as que mais contribuíram para variação entre e dentro da procedência. Caso a ANOVA fosse significativa, era posteriormente feito o teste de Tukey para identificar os diferentes grupos de progênies nas procedências, respectivamente.

ii) Em seguida, recorreu-se a análise de agrupamentos "cluster" (sobre a média das progênies), e representação em dendrograma para melhor ilustrar os resultados anteriores da ANOVA entre as diferentes procedências e progênies e, dessa forma, identificar e separar grupos superiores em relação as características de crescimento (altura, DAP e volume). Esse procedimento ajudará de certa forma a identificar quais progênies tiveram maior influência sobre o desempenho das procedências. $O$ método de aglomeração usado foi o Ward's e com a distância Euclidiana elevada ao quadrado, já que todas as variáveis eram contínuas. Foi recorrido ao valor do $\mathrm{Eta}^{2}$ (percentagem de variação entre os clusters), e um teste de média entre os grupos para definir o número ideal de clusters das procedências e progênies por reter, e assim, poder ter uma boa visão do padrão de variação conjunta entre as procedências e progênies.

iii) Após a identificação dos grupos, foram classificadas as 10 melhores progênies, com base no efeito genético aditivo predito e no ganho genético (seleção a $30 \%$ entre progênies). E com base no ganho genético da média geral do variável volume, foram também classificados os 20 melhores indivíduos (seleção a 3\% ao nível dos indivíduos das progênies dentro das procedências). Essa classificação teve como objetivo, selecionar as melhores progênies e indivíduos com maior produção volumétrica para as gerações posteriores de melhoramento e plantios comerciais. Para seleção da variável com maior influência na produtividade da progênie, foi usado o Coeficiente de Correão de Pearson (CCP) entre o volume e a altura ou DAP, dependendo da variável com maior CCP.

iv) As estimativas dos componentes da variância e dos parâmetros genéticos foram realizadas com base no método de máxima verossimilhança restrita (REML) individual das progênies, a partir do modelo estatístico 5 (testes de progênies de meios-irmãos), com delineamento de blocos ao acaso. Tal análise, foi feita com o auxílio do programa computacional SELEGEN-REML/BLUP (RESENDE 2014).

Os cálculos de componentes de variância foram obtidos pelas fórmulas propostas por (RESENDE 2007).

$$
h_{a}^{2}=\frac{\sigma_{a}^{2}}{\sigma_{f}^{2}}
$$

Onde: $h_{a}^{2}$ é a herdabilidade individual no sentido restrito; $\sigma_{a}^{2}$ é a variância genética aditiva; e ${ }^{\sigma_{f}^{2}}$ é a variância fenotípica individual.

$$
C V_{g i}(\%)=\frac{\sqrt{\sigma_{u}^{2}}}{R} \times 100
$$

Onde: $C V_{g^{i}}(\%)$ é o coeficiente de variação genética aditiva individual; e ${ }^{\bar{X}}$ é a média geral da população original.

$$
C V_{d}(\%)=\frac{\sqrt{\sigma_{d}^{2}}}{\pi} \times 100
$$
experimento.

Onde: $C V_{d}(\%)$ é o coeficiente de variação residual do experimento; e $\sigma_{d}^{2}$ é a variância residual do

As estimativas dos ganhos com a seleção das progênies foram obtidas de acordo com o proposto por (CRUZ 2012).

$$
G S(\%)=\frac{G S}{F_{0}} \times 100 \text {, sendo } G S=h_{a}^{2} \times D S
$$

Onde: ${ }^{G S}$ é o ganho genético por seleção; ${ }^{D S}$ é o diferencial de seleção; e $\bar{X}_{0}$ é a média geral da população original. 


$$
D S=\bar{X}_{s}-\bar{X}_{0}(6)
$$

Em que: $\bar{X}_{s}$ é a média das progênies selecionadas.

Também foi determinado o desempenho relativo (BURDON 1998, MORA 2002) para comparação da posição relativa entre as diferentes procedências, usando como recurso a Fórmula 7.

$$
D R=\frac{\bar{Z}-X_{\text {manar }}}{X_{\text {maior }}-x_{\text {menor }}} \times 100
$$

Onde: DR é o desempenho relativo (\%); $\bar{X}$ é altura média da procedência avaliada; $\mathrm{X}_{\text {menor }}$ é a procedência com o pior desempenho; e $X_{\text {maior }}$ é a procedência com melhor desempenho. Todas as análises foram feitas utilizando-se os softwares $R$ e SELEGEN.

\section{RESULTADOS}

\section{Desempenho relativo das procedências}

A Figura 3 apresenta o desempenho relativo das cinco procedências de $P$. tecunumanii nas idades de dois, quatro e oito anos. Pode-se observar que a procedência Yucul (YI) não só apresentou um desempenho superior, mas também manteve a mesma posição classificatório (desempenho relativo igual a $100 \%$ ) em todo o período. Villa Santa (VS) apresentou, em média, o segundo melhor desempenho relativo, principalmente nos anos dois e oito, tendo sido também relativamente estável, embora tenha sido ultrapassada pela San Rafael del Norte (SRN) no quarto ano.

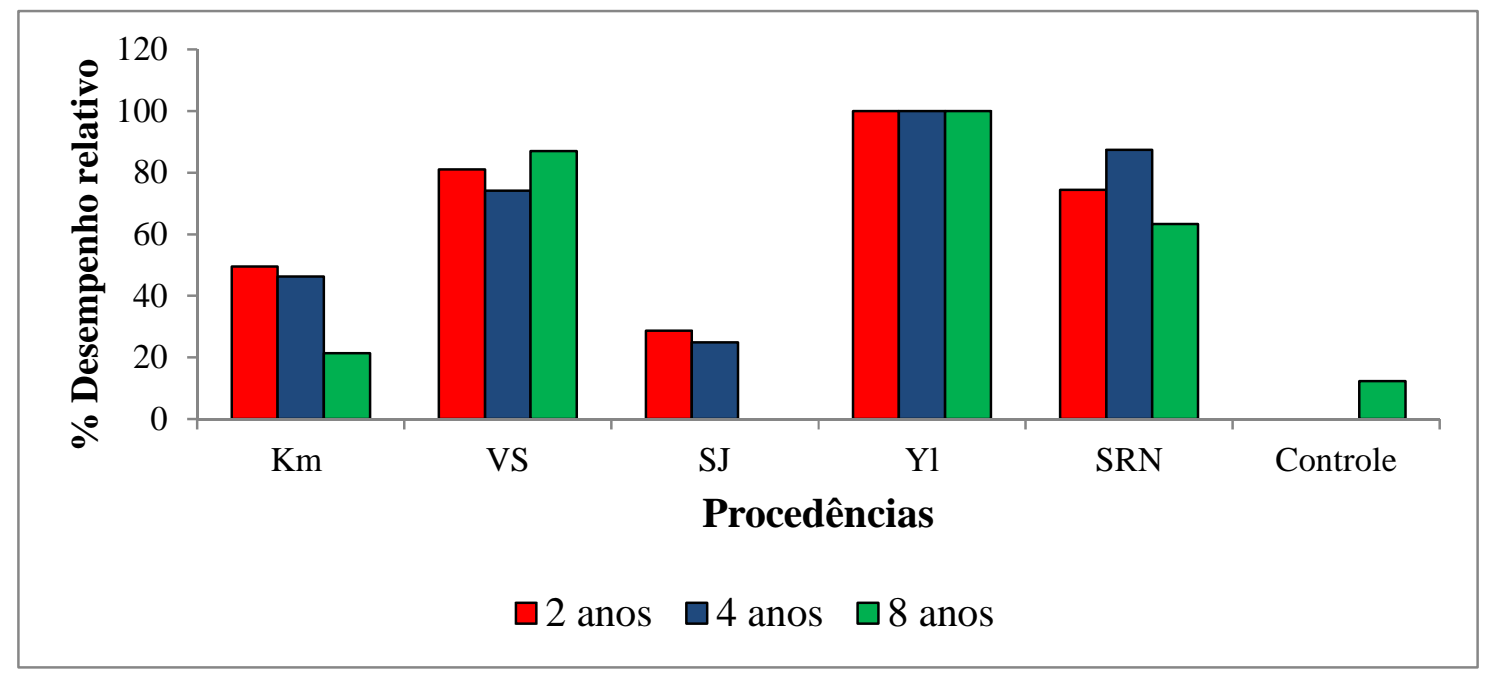

Figura 3. Desempenho relativo das procedências do $P$. Tecunumanii no distrito de Chimbonila, Moçambique.

Figure 3. Relative performance of P. tecunumanii provenances in Chimbonila district, Mozambique.

As procedências $\mathrm{Km} 33(\mathrm{Km})$ e San Jeronimo (SJ), não só apresentaram um desempenho muito abaixo das duas anteriores, mas também tenderam a reduzir com o avanço das idades. A testemunha do Zimbabwe apresentou o pior desempenho, tendo sido nulo nos dois primeiros anos e recuperando para $12,34 \%$ no último ano.

\section{Crescimento e adaptabilidade das procedências}

$\mathrm{Na}$ Tabela 2 são apresentados os resultados da ANOVA e teste de média (Tukey) das diferentes procedências de $P$. Tecunumanii, testadas no ambiente de Chimbonila.

As diferenças entre os níveis de sobrevivência não foram estatisticamente significativas nos dois anos estudados, tendo variado entre 93,75 a $100 \%$ no período em análise. San Rafael del Norte (SRN), apresentou $100 \%$ de sobrevivência nos dois anos, sendo que San Jerónimo (SJ), apresentou a pior sobrevivência tendo variado entre 94,45 e 93,75\% para o primeiro e último ano, respectivamente.

Os parâmetros altura, DAP e volume não foram estatisticamente significativos aos oito anos de idade. Houve diferença estatisticamente significativa $(\alpha=0,01)$, para a variável altura aos dois anos de idade, tendo se destacado superiores as procedências Yucul (YI), Villa Santa (VS) e San Rafael del Norte (SRN). No quarto ano, a procedência Yucul (YI) revelou-se superior em relação as restantes para a variável altura, embora não estatisticamente significativo quando comparadas com $\mathrm{Km} 33(\mathrm{Km})$, Villa Santa (VS) e San 
Rafael del Norte (SRN). O DAP foi relativamente alto para a procedência VS ( $\alpha=5 \%$ ), embora não estatisticamente diferente em relação as $\mathrm{Km}$, SJ, YI e SRN. Para a variável volume houve diferenças estatísticas $(\alpha=5 \%)$, aos quatros anos de idade, destacando-se as procedências VS, YI e SRN. Os coeficientes de variação do erro experimental (CV\%) entre procedências foi baixo para todos os parâmetros no quarto e oitavo ano de estudo com excepção do volume que foi de média magnitude no igual período em estudo.

Tabela 2. Médias de alturas, DAP, volumes e sobrevivência, por idades, das procedências de $P$. Tecunumanii no distrito de Chimbonila, Moçambique.

Table 2. Growth means (height, DBH and volume) and survival by age of the provenances of $P$. tecunumanii. in Chimbonila district, Mozambique.

\begin{tabular}{|c|c|c|c|c|c|c|c|c|c|}
\hline \multirow[t]{2}{*}{ Procedências } & \multicolumn{3}{|c|}{ Altura (m) } & \multicolumn{2}{|c|}{ DAP $(\mathrm{Cm})$} & \multicolumn{2}{|c|}{ Volume ( $\left.\mathrm{m}^{3} / a ́ r v.\right)$} & \multicolumn{2}{|c|}{ Sobrevivência (\%) } \\
\hline & 2 anos & 4 anos & 8 anos & 4 anos & 8 anos & 4 anos & 8 anos & 2 anos & 8 anos \\
\hline $\mathrm{Km}$ & $3,10 \mathrm{ab}$ & $5,97 \mathrm{abc}$ & 12,89 & $7,10 \mathrm{ab}$ & 14,26 & $0,0110 \mathrm{ab}$ & 0,0919 & 98,61 & 94,45 \\
\hline VS & $3,41 \mathrm{a}$ & $6,34 a b$ & 13,60 & $7,55 \mathrm{a}$ & 15,81 & $0,0126 a$ & 0,1156 & 98,22 & 95,84 \\
\hline SJ & $2,91 a b$ & 5,69 bc & 12,65 & $6,72 a b$ & 14,07 & $0,0093 a b$ & 0,0881 & 94,45 & 93,75 \\
\hline YI & $3,58 \mathrm{a}$ & $6,67 \mathrm{a}$ & 13,75 & $7,47 \mathrm{ab}$ & 14,91 & $0,0133 a$ & 0,1046 & 100,0 & 95,84 \\
\hline SRN & $3,34 \mathrm{a}$ & $6,51 \mathrm{ab}$ & 13,35 & $7,46 a b$ & 15,39 & $0,0126 a$ & 0,1084 & 100,0 & 100,0 \\
\hline Controle & $2,63 \mathrm{~b}$ & $5,36 \mathrm{c}$ & 12,79 & $6,29 \mathrm{~b}$ & 14,07 & $0,0072 \mathrm{~b}$ & 0,0850 & 97,92 & 97,92 \\
\hline Média $^{\top}$ & 3,16 & 6,09 & 13,17 & 7,10 & 14,75 & 0,0110 & 0,0989 & 98,20 & 96,30 \\
\hline$F$ & $5,71^{* *}$ & $8,43^{* \pi}$ & $1,82^{\text {ns }}$ & $3,32^{*}$ & $2,16^{\text {ns }}$ & $4,75^{\text {** }}$ & $2,02^{\text {ns }}$ & $1,51^{\text {ns }}$ & $1,97^{\text {ns }}$ \\
\hline$C V_{\exp }(\%)$ & 9,28 & 5,73 & 5,16 & 7,80 & 6,80 & 19,81 & 17,55 & 3,39 & 3,42 \\
\hline
\end{tabular}

Médias seguidas pela mesma letra na coluna não são estatisticamente diferentes pelo teste Tukey. ns = não significativo, ${ }^{*}=$ significativo a $5 \%,{ }^{* *}=$ significativo a $1 \%, 1$ = média geral das procedências, incluído a testemunha.

O Incremento Médio Anual (IMA em $\mathrm{m}^{3 *} \mathrm{ha}^{-1} \mathrm{ano}^{-1}$ ) de todas as procedências foi superior em relação ao controle (Figura 4). Os IMA's das procedências Km $33(\mathrm{Km})$, Yucul (YI), San Rafael del Norte (SRN) e Villa Santa (VS), produziram o equivalente a (150,88\% e 104,34\%), (184,82\% e $120,75 \%),(178,83 \%$ e $130,13 \%)$ e $(174,02 \%$ e $133,18 \%)$ do IMA do controle aos quatro e oito anos de idade, respectivamente. San Jerónimo (SJ) teve o IMA mais baixo comparativamente as restantes procedências, mas ainda modestamente alto em relação ao controle $(124,86 \%$ e $98,97 \%)$ para os anos quatro e oito respectivamente. No geral, a diferença entre o IMA das procedências e do controle, tendeu a reduzir com o passar do tempo.

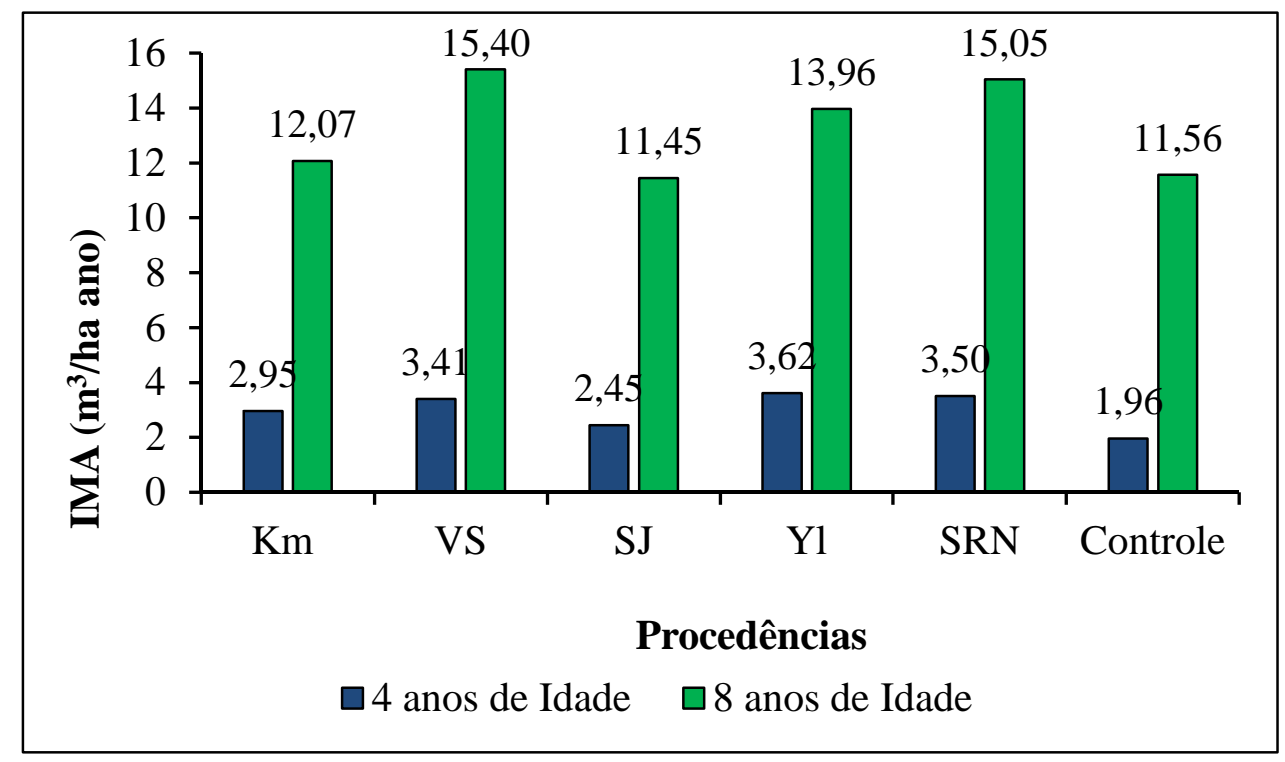

Figura 4. Incremento médio anual em volume das procedências do $P$. tecunumanii no distrito de Chimbonila, Moçambique.

Figure 4. Average annual increment (in volume) of the provenances of $P$. tecunumanii in Chimbonila district, Mozambique. 


\section{Variação do crescimento entre as progênies}

$\mathrm{Na}$ Tabela 3 são apresentados os resultados referentes ao teste de Tukey para os pares de média do desdobramento das procedências em progênies. O teste de Tukey, foi efetuado após a validação do pressuposto da ANOVA em relação as progênies para os parâmetros altura, DAP e volume aos oito anos de idade, conforme consta na Tabela A2 dos anexos. Também foi observado efeito significativo em relação ao local de estabelecimento do ensaio (blocos).

Tabela 3. Comparação entre médias das progênies e coeficiente de correlação entre Altura ou DAP com volume para $P$. tecunumanii, aos oito anos no distrito de Chimbonila, Moçambique.

Table 3. Comparison between means of progenies and correlation between height and DAP with volume for $P$. tecunumanii, at eight years old in Chimbonila district, Mozambique.

\begin{tabular}{|c|c|c|c|c|c|c|}
\hline País & Proveniências & Progênies & Altura $(\mathrm{m})$ & $\mathrm{DAP}(\mathrm{Cm})$ & $\operatorname{Vol}\left(m^{3}\right)$ & $\mathrm{CCP}$ \\
\hline Guatemala & $\mathrm{Km}$ & $13-2323$ & $13,22 \mathrm{abcd}$ & $15,09 \mathrm{abcd}$ & $0,1018 a b$ & 0,968 \\
\hline Guatemala & $\mathrm{Km}$ & $13-2326$ & $13,57 \mathrm{abcd}$ & $14,91 \mathrm{abcd}$ & $0,1044 a b$ & $0,932^{x \times}$ \\
\hline Guatemala & $\mathrm{Km}$ & $13-2399$ & $12,21 \mathrm{abcd}$ & $12,57 \mathrm{bcd}$ & $0,0650 a b$ & $0,987^{x \pi}$ \\
\hline Guatemala & $\mathrm{Km}$ & $13-2400$ & $11,68 \mathrm{~cd}$ & $12,20 \mathrm{~d}$ & $0,0587 \mathrm{~b}$ & $0,973^{* *}$ \\
\hline Guatemala & $\mathrm{Km}$ & $13-2402$ & $12,06 \mathrm{abcd}$ & $13,63 \mathrm{abcd}$ & $0,0781 a b$ & $0,938^{\star x}$ \\
\hline Guatemala & $\mathrm{Km}$ & $13-2403$ & $14,60 \mathrm{abc}$ & $17,17 \mathrm{a}$ & $0,1435 a$ & $0,96^{\star \pi}$ \\
\hline Honduras & VS & $16-2428$ & $13,72 \mathrm{abcd}$ & $16,44 \mathrm{abc}$ & $0,1293 a b$ & $0,945^{\star x}$ \\
\hline Honduras & VS & $16-2430$ & $13,45 \mathrm{abcd}$ & $16,08 \mathrm{abcd}$ & $0,1173 a b$ & $0,948^{* \pi}$ \\
\hline Honduras & VS & $16-2432$ & $12,62 \mathrm{abcd}$ & $14,21 \mathrm{abcd}$ & $0,0862 a b$ & $0,954^{\pi *}$ \\
\hline Honduras & VS & $16-2437$ & $14,36 \mathrm{abc}$ & $16,02 \mathrm{abcd}$ & $0,1232 a b$ & $0,965^{x \pi}$ \\
\hline Honduras & VS & $16-2438$ & $13,29 \mathrm{abcd}$ & $15,87 \mathrm{abcd}$ & $0,1140 a b$ & $0,956^{\pi *}$ \\
\hline Honduras & VS & $16-2439$ & $14,82 a b$ & $15,92 \mathrm{abcd}$ & $0,1256 a b$ & $0,933^{x \pi}$ \\
\hline Honduras & VS & $16-2440$ & $13,0 \mathrm{abcd}$ & $16,15 \mathrm{abcd}$ & $0,1137 a b$ & $0,67^{\pi \times}$ \\
\hline Guatemala & SJ & $13-2442$ & $12,14 \mathrm{abcd}$ & $13,46 \mathrm{abcd}$ & $0,0735 a b$ & $0,971^{\star x}$ \\
\hline Guatemala & SJ & $13-103$ & $14,48 \mathrm{abc}$ & $16,74 a b$ & $0,1423 \mathrm{a}$ & $0,952^{x \pi}$ \\
\hline Guatemala & SJ & $13-1103$ & $12,98 \mathrm{abcd}$ & $14,25 \mathrm{abcd}$ & $0,0889 a b$ & $0,953^{x *}$ \\
\hline Guatemala & SJ & $13-2324$ & $11,17 d$ & $12,51 \mathrm{~cd}$ & $0,0614 \mathrm{c}$ & $0,944^{\pi \times \psi}$ \\
\hline Guatemala & SJ & $13-2344$ & $11,97 \mathrm{bcd}$ & $12,86 \mathrm{bcd}$ & $0,0668 a b$ & $0,954^{\pi *}$ \\
\hline Guatemala & SJ & $13-2356$ & $13,17 \mathrm{abcd}$ & $14,61 \mathrm{abcd}$ & $0,0957 a b$ & $0,915^{* x}$ \\
\hline Nicarágua & YI & $16-2408$ & $13,03 \mathrm{abcd}$ & $13,60 \mathrm{abcd}$ & $0,0812 a b$ & $0,972^{x \times}$ \\
\hline Nicarágua & $Y I$ & $16-2409$ & $14,62 \mathrm{abc}$ & $15,03 \mathrm{abcd}$ & $0,1102 a b$ & $0,951^{\star x}$ \\
\hline Nicarágua & YI & $16-2417$ & $15,06 \mathrm{a}$ & $16,06 \mathrm{abcd}$ & $0,1334 a b$ & $0,936^{* \pi}$ \\
\hline Nicarágua & YI & $16-2418$ & $12,48 \mathrm{abcd}$ & $12,88 \mathrm{bcd}$ & $0,0690 a b$ & $0,947^{* *}$ \\
\hline Nicarágua & $Y I$ & $16-2420$ & $14,01 \mathrm{abcd}$ & $15,75 \mathrm{abcd}$ & $0,1163 a b$ & $0,97^{* \pi}$ \\
\hline Nicarágua & YI & $16-2424$ & $12,98 \mathrm{abcd}$ & $15,05 \mathrm{abcd}$ & $0,0985 a b$ & $0,953^{* x}$ \\
\hline Nicarágua & $\mathrm{YI}$ & $16-2425$ & $14,07 \mathrm{abcd}$ & $15,97 \mathrm{abcd}$ & $0,1234 a b$ & $0,966^{\pi x}$ \\
\hline Nicarágua & SRN & $16-2460$ & $12,89 \mathrm{abcd}$ & $14,37 \mathrm{abcd}$ & $0,0917 a b$ & $0,954^{* *}$ \\
\hline Nicarágua & SRN & $16-2461$ & $13,81 \mathrm{abcd}$ & $16,40 \mathrm{abcd}$ & $0,1250 a b$ & $0,963^{* x}$ \\
\hline \multirow[t]{2}{*}{ Zimbabwe } & & Common lot & $12,79 \mathrm{abcd}$ & $14,07 \mathrm{abcd}$ & $0,0850 a b$ & $0,956^{\pi *}$ \\
\hline & & DMS & 3,08 & 4,23 & 0,08 & \\
\hline
\end{tabular}

Médias seguidas pela mesma letra na mesma coluna não diferem significativamente pelo teste Tukey para ( $p \leq 5 \%$; DMS = Diferença mínima significativa para o teste. CCP $=$ Coeficiente de correlação de Pearson, ${ }^{* *}$ significante para $(p$ $=0,1)$. Valores com o símbolo Psi $(\Psi)$ representam correlação entre volume e altura e valores sem Psi $(\Psi)$, representam correlação entre volume e DAP.

Para a variável altura, a progênie 16-2417 da proveniência YI, apresentou superioridade em relação as restantes, embora não tenha sido estatisticamente superior em relação as várias progênies das mesmas (YI) e das restantes procedências, excluindo Km (13-2400) e SJ (13-2324; 13-2344). Em relação a mesma variável (HT), as outras progênies que mostraram um bom desempenho seguindo a YI (16-2417), foram as YI (16-2409), SY (13-103), VS (16-2439, 16-2437) e Km (13-2403). A pior progênie para a mesma variável (HT) foi a SJ (13-2324). 
Para a variável DAP, a média da progênie $\mathrm{Km}(13-2403)$ diferiram estatisticamente $(\alpha=1 \%)$ das progênies das restantes proveniências, tendo se destacado como as melhores progênies do ensaio. A progênie $\mathrm{Km}$ (13-2400), foi o pior tratamento do ensaio para a variável DAP. Em relação ao volume, as progênies Km (13-2403) e SJ (13-103), apresentaram-se como as melhores e estatisticamente superiores $(\alpha=1 \%)$ as restantes, contrariamente à SJ (13-2324) que foi a pior progênie do ensaio.

Os Coeficientes de Correlação de Person (CCP) marcados com o símbolo Psi ( $\Psi$ ), (ver a última coluna da Tabela 3), indica uma forte correlação entre o volume e altura, sendo que os não sinalizados indicam forte correlação entre o volume e DAP. Observa-se que, quase todas as progênies apresentaram forte correlação (volume e DAP), exceto SJ (13-2324) que teve uma correlação forte ente o volume e altura. O CCP esteve fortemente correlacionado $(>0.9)$ para todas as progênies, e consequentemente altamente significativo $(p=0,01)$, exceto para VS $(16-2440)$, que ficou em 0,67 .

Os resultados do agrupamento cluster estão disponíveis na Tabela 4 e na Figura 5, onde pode-se observar que, a solução de três clusters foi a melhor escolha, visto que a separação entre os grupos para todas as variáveis ficou acima dos $80 \%\left(\mathrm{Eta}^{2}>0,8\right)$.

Tabela 4. Valores de ANOVA, $\mathrm{Eta}^{2}$ e teste de Tukey para os clusters das diferentes progênies e Procedências no distrito de Chimbonila, Moçambique.

Table 4. Results from ANOVA, Eta ${ }^{2}$ and Tukey test of means for clusters of the different progenies and provenances in Chimbonila district, Mozambique.

\begin{tabular}{|l|c|c|c|c|c|c|}
\hline & Cluster 1 & Cluster 2 & Cluster 3 & Total & & \\
\cline { 2 - 8 } & $12(41,38 \%)$ & $7(24,14 \%)$ & $10(34,48 \%)$ & $29(100 \%)$ & $\mathrm{F}$ & Eta $^{2}$ \\
\hline Altura $(\mathrm{m})$ & $13,93 \mathrm{a}$ & $12,97 \mathrm{~b}$ & $11,70 \mathrm{c}$ & 12,93 & $57,64^{\star \star *}$ & 0,816 \\
DAP $(\mathrm{cm})$ & $15,92 \mathrm{a}$ & $14,40 \mathrm{~b}$ & $12,66 \mathrm{c}$ & 14,43 & $100,54^{\star \star *}$ & 0,886 \\
VOL $\left(\mathrm{m}^{3}\right)$ & $0,125 \mathrm{a}$ & $0,096 \mathrm{~b}$ & $0,071 \mathrm{c}$ & 0,100 & $116,95^{\star * *}$ & 0,900 \\
\hline
\end{tabular}

Valores com mesma letra na linha, não diferem estatisticamente pelo teste de Tukey; ${ }^{* * *}=$ Significante para $p \leq 0,01$.

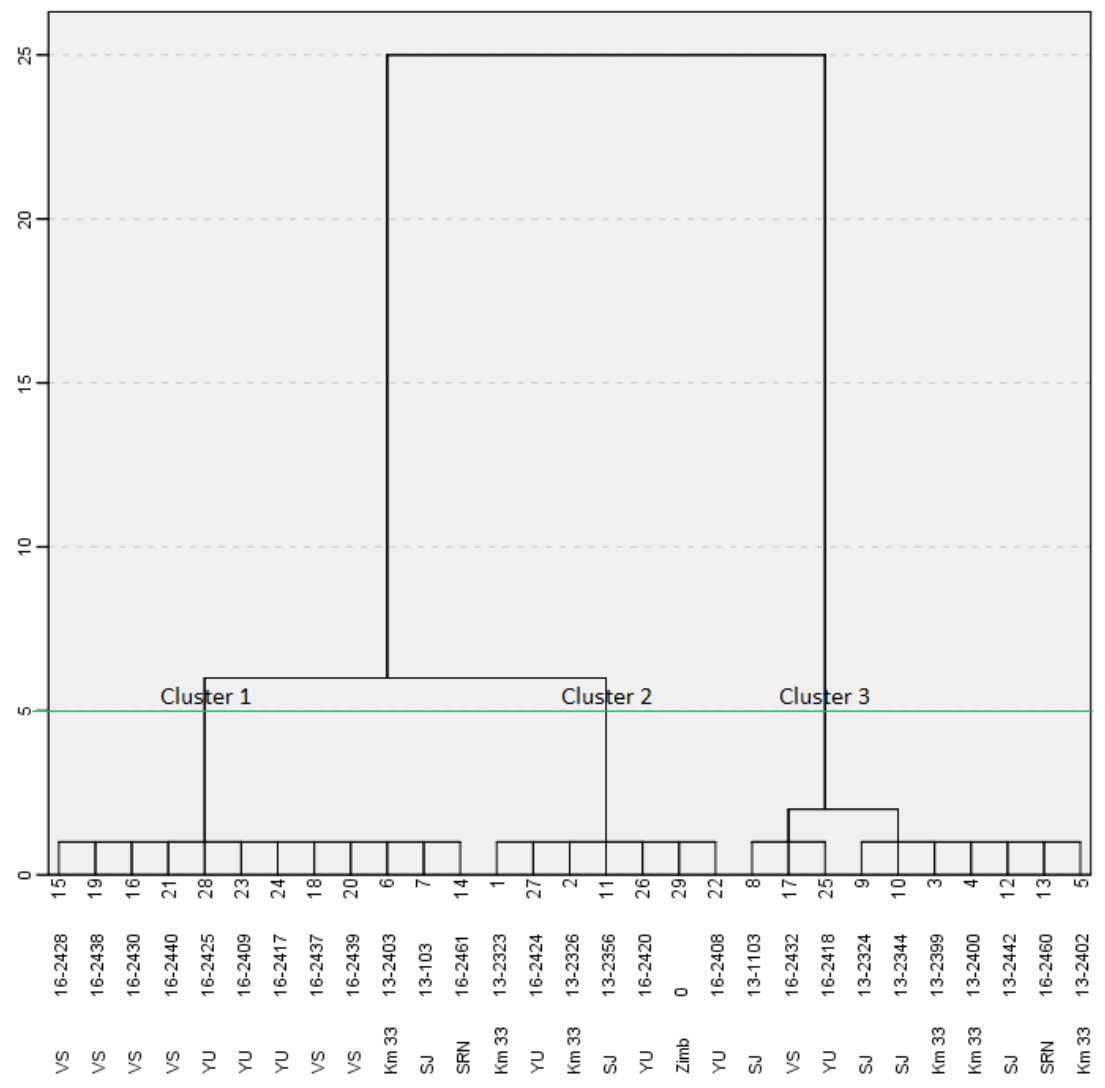

Figura 5. Agrupamento de cluster (dendrograma) das diferentes progênies e Procedências de $P$. tecunumanii aos oito anos de idade no distrito de Chimbonila, Moçambique.

Figure 5. Cluster dendrogram of the different progenies and procedures of $P$. tecunumanii at eight years of age in Chimbonila district, Mozambique. 
O primeiro cluster é composto pelas 12 (41,38\%) melhores progênies, maioritariamente das procedências Villa Santa (VS) e Yucul (YI) e apresentam superioridade em todos os parâmetros (altura, DAP e volume). No segundo cluster de sete $(24,14 \%)$, visivelmente o mais reduzido, constam progênies intermediárias do primeiro em último cluster. Maior parte das progênies do segundo cluster pertencem as procedências $\mathrm{Km} 33(\mathrm{Km})$ e Yucul $(\mathrm{Yl})$. A testemunha, também pertence ao segundo cluster. No último cluster, constam $10(34,48 \%)$ progênies que apresentaram o pior desempenho, na sua maioria pertencentes a San Jeronimo (SJ) e Km 33 (Km).

\section{Seleção de progênies com base em caracteres fenotípicos}

Na Tabela 6 estão apresentadas estimativas das componentes de variância e parâmetro genético das progênies de $P$. tecunumanii, aos oito anos de idade. Observa-se que ao desmembrar as componentes de variância individual, maior parte da variância fenotípica total de todos os parâmetros estudados, foi devido a variância genética aditiva $\left(\sigma_{a}^{2}\right)$ e variância fenotípica individual $\left(\sigma_{f}^{2}\right)$. A herdabilidade individual no sentido restrito $\left(h_{a}^{2}\right)$, também foi elevada. Todavia, os coeficientes de determinação do efeito da parcela $\left(\mathbb{C}_{\sharp}^{2}\right)$, e do efeito das procedências $\left(C_{p}^{2}\right)$, apresentaram valores de baixa magnitude. O coeficiente de variação genética aditiva individual ( $C V_{g i} \%$ ), foi alto para as variáveis altura e DAP e muito alto para a variável volume. Por último, os coeficientes de variação genotípica entre progênies ( $C V_{g p} \%$ ) e variação residual ( $C V_{d} \%$ ), foram de magnitude média para todas as variáveis.

Tabela 6. Estimativa dos Componentes de Variância (REML Individual) e parâmetro genético das progênies de $P$. tecunumanii, aos oito anos de idade no distrito de Chimbonila, Moçambique.

Table 6. Estimation of the Component of Variance (Individual REML) and the genetic parameter of the progenies of $P$. tecunumanii, at eight years of age in Chimbonila district, Mozambique.

\begin{tabular}{l|l|l|l}
\hline Variâncias & Altura $(\mathrm{m})$ & DAP $(\mathrm{cm})$ & Volume $\left(\mathrm{m}^{3}\right)$ \\
\hline$\sigma_{a}^{2}$ & 3,252146 & 6,653816 & 0,001971 \\
$\sigma_{g}^{2}$ & 0,567375 & 0,795542 & 0,000316 \\
$\sigma_{p}^{2}$ & 0,098797 & 0,250560 & 0,000029 \\
$\sigma_{d}^{2}$ & 1,164413 & 2,334870 & 0,000256 \\
$\sigma_{f}^{2}$ & 5,082731 & 10,034788 & 0,002573 \\
$h_{a}^{2}$ & $0,639842 \pm 0,1787$ & $0,663075 \pm 0,1819$ & $0,766046 \pm 0,1956$ \\
$C_{g}^{2}$ & 0,111628 & 0,079278 & 0,122842 \\
$C_{p}^{2}$ & 0,019438 & 0,024969 & 0,011460 \\
$C V_{a i}$ & 13,936305 & 17,835384 & 44,276610 \\
$C V_{g p}$ & 6,968153 & 8,917692 & 22,138305 \\
$c V_{d}$ & 8,351741 & 9,818313 & 24,534187 \\
\hline
\end{tabular}

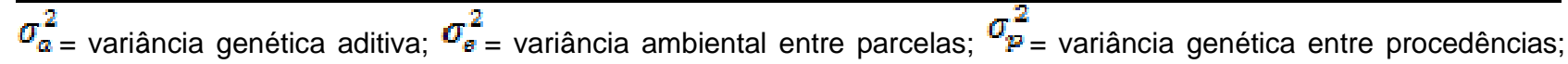

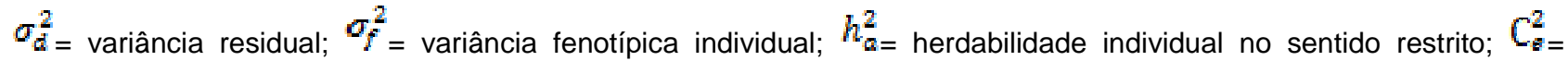
coeficiente de determinação dos efeitos de parcela; $C_{p}^{2}=$ coeficiente de determinação dos efeitos de procedências; $C V_{g i \%=}$ coeficiente de variação genética aditiva individual; $C V_{g p \%=}$ coeficiente de variação genotípica entre progênies; $C V_{d \%=}$ coeficiente de variação residual.

Com base no efeito genético aditivo predito (a) e no ganho genético, foram então classificadas as dez melhores progênies, correspondente a $35 \%$ da seleção de genitores através do volume, conforme consta na Tabela 7. Observa-se que procedência Villa Santa (VS), teve maior número de progênies selecionados, perfazendo mais da metade das progênies, sendo que as quatro procedências restantes, contribuíram com apenas uma progênie cada.

Na Tabela 8, apresenta-se a classificação desejável dos 20 (3\%) melhores indivíduos selecionados nas 28 progênies de Pinus tecunumanii para continuidade de melhoramento genético. $O$ critério de classificação foi com base no ganho genético da média geral do variável volume. Como já era de esperar, observa-se novamente a predominância dos indivíduos da procedência Villa Santa (VS), perfazendo 
aproximadamente metade (45\%), sendo a progênie 16-2428, a mais predominante. Seguidas pelas procedências San Jeronimo (SJ), Km $33(\mathrm{Km})$ e San Rafael del Norte (SRN), tendo cada uma contribuído de forma equitativa com três progênies e por último Yucul (YI), que contribui com apenas duas progênies.

Tabela 7. Seleção das 10 (35\%) melhores progênies de $P$. Tecunumanii aos oito anos de idade no distrito de Chimbonila, Moçambique.

Table 7. Selection of the 10 (35\%) best progenies of P. tecunumanii at eight years of age in Chimbonila district, Mozambique.

\begin{tabular}{c|c|c|c|c|c}
\hline Ordem & Procedências & Progênies & a & Ganho & Nova Média \\
\hline 1 & SJ & $13-103$ & 0,0646 & 0,0646 & 0,1648 \\
2 & Km & $13-2403$ & 0,0611 & 0,628 & 0,1631 \\
3 & SRN & $16-2461$ & 0,0427 & 0,0561 & 0,1564 \\
4 & VS & $16-2439$ & 0,0384 & 0,0517 & 0,1520 \\
5 & VS & $16-2437$ & 0,0371 & 0,0488 & 0,1490 \\
6 & VS & $16-2428$ & 0,0353 & 0,0465 & 0,1468 \\
7 & VS & $16-2438$ & 0,0333 & 0,0446 & 0,1449 \\
8 & YI & $16-2417$ & 0,0329 & 0,0432 & 0,1434 \\
9 & VS & $16-2430$ & 0,0322 & 0,0420 & 0,1422 \\
10 & VS & $16-2440$ & 0,0283 & 0,0406 & 0,1409 \\
\hline
\end{tabular}

a: efeito genético aditivo predito.

Tabela 8. Classificação dos 20 (3\%) melhores indivíduos de $P$. tecunumanii dentro das progênies aos oito anos de idade no distrito de Chimbonila, Moçambique.

Table 8. Classification of the 20 (3\%) best individuals of P. tecunumanii selected within progenies at eight years of age in Chimbonila district, Mozambique.

\begin{tabular}{c|c|c|c|c|c|c|c|c|cc}
\hline Ordem & Bloco & Prog. & Proc. & Árv. & $\mathrm{f}$ & $\mathrm{a}$ & $\mathrm{U}+\mathrm{a}$ & Ganho & Nova Média & $\mathrm{Ne}$ \\
\hline 1 & 1 & 2438 & VS & 4 & 0,3770 & 0,2135 & 0,3138 & 0,2135 & 0,3138 & 1,0000 \\
2 & 1 & 103 & SJ & 2 & 0,4101 & 0,2109 & 0,3111 & 0,2122 & 0,3125 & 2,0000 \\
3 & 1 & 2417 & YI & 5 & 0,3149 & 0,1347 & 0,2350 & 0,1864 & 0,2866 & 3,0000 \\
4 & 1 & 2428 & VS & 6 & 0,3006 & 0,1330 & 0,2333 & 0,1730 & 0,2733 & 4,0000 \\
5 & 1 & 2428 & VS & 1 & 0,2692 & 0,1062 & 0,2064 & 0,1597 & 0,2599 & 4,4944 \\
6 & 1 & 2430 & VS & 2 & 0,2499 & 0,1057 & 0,2059 & 0,1507 & 0,2509 & 5,4962 \\
7 & 3 & 2460 & SRN & 6 & 0,2329 & 0,1048 & 0,2051 & 0,1441 & 0,2444 & 6,4972 \\
8 & 1 & 2428 & VS & 2 & 0,2597 & 0,0981 & 0,1984 & 0,1384 & 0,2386 & 6,6207 \\
9 & 3 & 2461 & SRN & 4 & 0,1973 & 0,0929 & 0,1932 & 0,1333 & 0,2336 & 7,6107 \\
10 & 4 & 2403 & Km & 1 & 0,1983 & 0,0912 & 0,1915 & 0,1291 & 0,2294 & 8,6022 \\
11 & 3 & 2403 & Km & 6 & 0,1925 & 0,0892 & 0,1895 & 0,1255 & 0,2257 & 9,2097 \\
12 & 2 & 103 & SJ & 6 & 0,2012 & 0,0881 & 0,1883 & 0,1224 & 0,2226 & 9,8341 \\
13 & 4 & 2417 & YI & 2 & 0,1769 & 0,0860 & 0,1862 & 0,1196 & 0,2198 & 10,4719 \\
14 & 2 & 2440 & VS & 6 & 0,2117 & 0,0850 & 0,1853 & 0,1171 & 0,2174 & 11,4406 \\
15 & 1 & 2438 & VS & 2 & 0,2229 & 0,0821 & 0,1824 & 0,1148 & 0,2150 & 12,0805 \\
16 & 4 & 2461 & SRN & 6 & 0,1759 & 0,0813 & 0,1816 & 0,1127 & 0,2129 & 12,7293 \\
17 & 1 & 2440 & VS & 1 & 0,2026 & 0,0801 & 0,1804 & 0,1108 & 0,2110 & 13,3857 \\
18 & 3 & 103 & SJ & 2 & 0,1646 & 0,0794 & 0,1797 & 0,1090 & 0,2093 & 13,7143 \\
19 & 1 & 2439 & VS & 2 & 0,2160 & 0,0786 & 0,1789 & 0,1074 & 0,2077 & 14,6533 \\
20 & 3 & 2403 & Km & 3 & 0,1783 & 0,0771 & 0,1774 & 0,1059 & 0,2062 & 15,0000 \\
\hline
\end{tabular}

$\mathrm{F}=$ valor fenotípico individual ou medição de campo; $\mathrm{a}=$ efeito genético aditivo predito; $\mathrm{U}+\mathrm{a}=$ valor genético aditivo predito; $\mathrm{Ne}=$ tamanho efetivo populacional. 


\section{DISCUSSÃO}

\section{Crescimento e produção das procedências e progênies}

Os resultados de crescimento e adaptabilidade de procedências de $P$. tecunumanii do ensaio estabelecido no ambiente de Chimbonila, demostrou uma precisão experimental aceitável, visto que os coeficientes de variação do erro experimental para quase todos os parâmetros estudados foram de baixa magnitude. A prova disso, prende-se também pelo fato de o efeito dos blocos ter sido estatisticamente significativo, indicativo de que o erro aleatório devido a variabilidade do sítio foi bem controlado pelo delineamento experimental escolhido. Existem ensaios semelhantes que encontraram coeficientes de variação que estiveram próximos do presente estudo (SILVA et al. 2011)), mas outros também que tiverem coeficientes ligeiramente acima, como é o caso de VIEIRA \& SHIMIZU (1998).

O nível de sobrevivência elevado (acima de $90 \%$ ) e não estatisticamente significativo em relação ao controle, principalmente no último ano de avaliação, e com CV de variação de alta precisão, mostra um bom potencial de adaptabilidade para proveniências de $P$. tecunumanii que foram introduzidas pela primeira vez no ambiente de Chimbonila. Os valores de sobrevivência estão acima dos encontrados em zonas destacadas como de forte potencial de adaptabilidade para espécie na América Latina (CARPENTER et al. 2004) e em África (NYOKA et al. 2010).

Não é de se surpreender o fato do CV do variável volume ter sido alto, já que este foi derivado do produto entre altura e o DAP ${ }^{2}$. Mas de uma forma geral, o delineamento experimental foi bastante confiável para captar o crescimento e adaptabilidade de procedências e progênies de $P$. tecunumanii no ambiente de Chimbonila, visto que, os valores dos coeficientes de variação das variáveis mensuradas ficaram abaixo dos $20 \%$ conforme recomendado por PIMENTAL GOMES (1990).

As proveniências Villa Santa (VS), San Rafael del Norte (SRN) e Yucul (YI), tem maior proximidade com local de introdução relativamente aos fatores edafoclimáticos (altitude e clima), e consequentemente maior potencial produtivo e de adaptabilidade. Não tendo sido nenhuma surpresa o fato de as mesmas terem apresentado um desempenho superior em quase todos os parâmetros de crescimento e adaptabilidade estimados (sobrevivência, desempenho relativo, volume e crescimento médio anual). Porém, isto mostra que existe necessidade de priorizar a seleção de procedências para introdução em novos ambientes em função dos fatores edafoclimáticos. O incremento médio anual das mesmas procedências esteve muito acima do controle, mas também acima dos resultados de outros estudos (HONGWANE et al. 2017), MOREIRA 2017)), devendo-se provavelmente ao período quente e chuvoso que é relativamente longo em Chimbonila, comparativamente as outras regiões, conforme mostra MBANZE et al. (2013) e MBANZE et al. (2015), o que dá maior vantagem fotossintética. BRAWNER et al. (2014), demostraram que de entre várias variáveis ambientais a precipitação e temperatura desempenham um papel preponderante no desempenho que $P$. tecunumanii no ambiente introduzido.

\section{Seleção e adaptabilidade das progênies}

O teste de média entre procedências não apresenta muita diferença significativa entre os pares de média das procedências, para todos os parâmetro no período de estudo, principalmente entre Villa Santa (VS), Yucul (YI), Km $33(\mathrm{Km})$ e San Rafael del Norte (SRN), com exceção do controle que mostra claramente um fraco desempenho, abaixo do esperado se comparado com as procedências introduzidas. Porém, o desdobramento das análises a nível das progênies já mostra alguns grupos distintos de bom e mau desempenho, indicativo de que nem todas as progênies contribuem da mesma forma para 0 desempenho global da procedência. De fato, existe um grupo modesto de 41,38\% progênies, com maior contribuição no desempenho das procedências, como foi possível identificar com auxílio de análise de cluster. Essas progênies são predominantemente das procedências Villa Santa (VS) e Yucul (YI), sendo necessário alargar para o segundo cluster de modo a cobrir $\mathrm{Km} 33(\mathrm{Km})$.

No entanto, em função das análises de cluster, representação em dendrograma e auxílio das análises do efeito aditivo predito (a) e do ganho genético, foi possível selecionar as 10 melhores progênies com potencial para a segunda geração de programa de melhoramento. Porém, a maximização dos ganhos é mais bem alcançada quando se faz a classificação dos 20 melhores indivíduos, alcançando ganhos acima do dobro da seleção por progênies, com apenas 33\% dos indivíduos da seleção por progênies, o que reduziria drasticamente os custos de um programa de melhoramento. Adicionalmente, a herdabilidade individual no sentido restrito, que quantifica a importância relativa da proporção aditiva da variância genética que pode ser transmitida para a próxima geração, foi alto para todas as variáveis, indicativo de que a seleção com base em plantas individuais seria mais eficiente. 
Como já era de esperar, a partir da análise de clusters e da seleção dentro das procedências, a maior parte dos 20 indivíduos selecionados pertencem à progênie Villa Santa (VS), o que mostra a eficiência e versatilidade da metodologia adotada de seleção hierárquica, descendo de procedência até ao nível individual. Um caso bastante curioso, prende-se com o fato de que, $50 \%$ dos 20 melhores indivíduos selecionados, na sua maioria Villa Santa (VS), estiverem no primeiro bloco. Embora já era de esperar, visto que ANOVA ao nível das progênies detectou efeito significativo dos blocos no delineamento experimental, mas não na proporção encontrada. Isso provavelmente esteja relacionado com a localização de manchas mais férteis ou melhor retenção da umidade no solo. Todavia, o coeficiente de determinação dos efeitos da parcela ( $c^{2}$ parc) apresentou valores de baixa magnitude, indicativo de que o delineamento de blocos ao acaso foi eficiente no controle ambiental.

O coeficiente de variação genética aditiva individual foi considerado alto para as variáveis altura e DAP e muito alto para a variável volume, o que indica um ótimo potencial para seleção de progênies ou até mesmo indivíduos, com base no volume. Mas como o volume é uma variável de difícil acesso, pode ser usada a variável DAP, que apresentou uma forte correlação com o volume para quase todas as progênies. Valores de Coeficiente de Correlação elevados (CC $\geq 90 \%$ ) entre o volume e DAP em ensaios de procedências e progênies de $P$. Tecunumanii foram também encontrados em ensaios semelhantes na América Latina (DE SOUZA et al. 2016) e numa zona próxima de Chimbonila no país vizinho (MUNTHALI \& STEWAR 1998).

\section{CONCLUSÃO}

Os resultados do presente estudo sugerem um bom crescimento e adaptabilidade das cinco procedências de $P$. tecunumanii no ambiente de Chimbonila, principalmente em relação à testemunha.

O método de seleção hierárquica, começando ao nível de procedências e descendo até aos indivíduos, mostrou-se bastante aceitável para o presente ensaio, tendo sido verificado maiores ganhos ao nível individual, predominantemente por indivíduos da procedência Villa Santa (VS).

A forte correlação entre o volume e DAP para maior parte das progênies, sugere que a seleção das progênies pode ser feita a partir da DAP que é uma variável de fácil acesso.

\section{AGRADECIMENTOS}

Os autores agradecem a Empresa Florestas de Niassa Lda, aos Engenheiros José Bernardo Manteiga, David Machiana e Custódio da Conceição e aos senhores John Mkumbira, Hélio Raul, Abudo Issufo, Candawele Abudo e Agostinho Adriano, pela assistência e colaboração durante a coleta dos dados. Ao professor Júlio Arce da Universidade Federal do Paraná (UFPR) no Brasil, pela revisão do manuscrito.

\section{REFERÊNCIAS}

AGUIAR A et al. 2011. Programa de melhoramento de pinus da Embrapa Florestas. Colombo: Embrapa. p.21.

BRAWNER JT et al. 2014. Visualising the environmental preferences of Pinus tecunumanii populations. Tree Genetics and Genomes 10: 1123-1133.

BURDON RD. 1998. Relative performance values in genetic tests: Alternatives and their properties. Silvae Genetica 47: 1-5.

CARPENTER FL et al. 2004. Early growth of native and exotic trees planted on degraded tropical pasture. Forest Ecology and Management 196: 367-378.

CERDA-GRANADOS D \& DÍAZ V. 2013. Optimizacion de un protocolo de extraccion de ADN genómico para Pinus tecunumanii 94: 82-92.

CRUZ CD. 2012. Princípios de genética quantitativa. 2.ed. Viçosa: UFV. 394p.

DE SOUZA FB et al. 2016. Selection of Pinus species and provenances for Assis region, State of São Paulo. Scientia Forestalis/Forest Sciences 44: 675-682.

DVORAK WS et al. 1993. Genetic and site effects on stem breakage in Pinus tecunumanii. New Forests 7: $237-253$.

EGUILUZ-PIEDRA T \& PERRY J. 1983. Pinus Tecunumanii: Una Especie Nueva de Guatemala. Revista Ciencia Florestal 8: 1-20.

GAPARE W et al. 2001. Genetic Parameters And Provenance Variation Of $P$. maximinoi in Brazil, Colombia And South Africa. Forest Genetics 8: 160-165.

HODGE G \& DVORAK W. 1999. Genetic Parameters And Provenance Variation Of $P$. tecunumanii in 78 International Trials. Forest Genetics 6: 161-173.

HONGWANE PC et al. 2017. Growth and dynamic modulus of elasticity of Pinus patula $\times$ Pinus tecunumanii hybrids in Mpumalanga, South Africa. Southern Forests 79: 277-285. 
INDE. 2009. Instituto Nacional do Desenvolvimento da Educação. Atlas de Moçambique. Maputo: Editora Nacional de Moçambique S.A.

INVUA S. 2014. Avaliação da Influência da Preparacão do Solo no Desempenho Eucalyptus urograndis, no Distrito de Lichinga no Campo de Ensaio da Empresa Niassa Green Resources. Monografia (Licenceatura em Engenharia Florestal). Distrito de Sanga: UniLúrio. 58p.

KARIUKI JG. 1998. Provenance and family-within-provenance variation in Pinus patula, Pinus patula subspecies tecunumanii and Pinus oocarpa planted at Turbo, Kenya. Forest Ecology and Management 107: 127-133.

LANDRY J \& CHIRWA PW. 2011. Analysis of the potential socio-economic impact of establishing plantation forestry on rural communities in Sanga district, Niassa province, Mozambique. Land Use Policy 28: 542-551.

LÓPEZ JL. 2014. Camcore Trip Report to Florestas de Niassa. North Carolina. 12p. (Documento).

MAE. 2014. Ministério da Administração Estatal. Perfil do Distrito de Chimbonila-Lichinga, Provincia de Niassa. Maputo: MAE. 68p.

MBANZE AA et al. 2015. Influence of the meteorological conditions on forest fires occurrences in Lichinga District, Northern Mozambique. Floresta 45: 577-586.

MBANZE AA et al. 2013. Assessment of causes that contribute to the occurrence of plantations forests fires in Niassa Province, North of Mozambique. African Journal of Agricultural Research 8: 5684-5691.

MINISTÉRIO DA AGRICULTURA. 2006. Estratégia National de Reflorestamento - Por um Desenvolvimento de Plantações Florestais Sustentáveis. (Documento para discussão) 22p.

MORA AL. 2002. Aumento da Produção de Sementes Geneticamente Melhoradas de Acacia mearnsii de Wild. (Acácianegra) no Rio Grande do Sul. Tese (Doutorado em Engenharia Florestal). Curitiba: UFP. 161p.

MOREIRA JP. 2017. Produtividade, Estabilidade, Adaptabilidade e Diversidade Genética em Testes de Progênies de Pinus caribaea var. hondurensis e Pinus tecunumanii. Tese (Doutorado em Agronomia) llha Solteira: UNESP. 85p.

MUNTHALI CRY \& STEWAR M. 1998. Growth of nine-year-old provenance and taxonomy trials of pinus tecunumanii at zomba and chongoni, Malawi. Southern African Forestry Journal 181: 13-19.

NHANTUMBO L. 2014. Avaliação do comportamento de diferentes proveniências de Corymbia citriodora aos 12 meses no Distrito de Lichinga. In: 3ª Jornadas científicas Moçambique: Universidade Lúrio.

NUBE TG et al. 2016. Impactos Socioeconômicos das Plantações Florestais no Niassa, Moçambique 23: 52-60.

NYOKA BI et al. 2010. Provenance productivity of high and low elevation Pinus tecunumanii in Zimbabwe. Silvae Genetica 59: 189-199.

OVERBEEK W. 2010. The Expansion of Tree Monocultures in Mozambique. Impacts on Local Peasant Communities in the Province of Niassa. Montevideo: WRM. 27p. (Series on tree plantations no 14).

PIMENTAL GOMES F. 1990. Curso de Estatistica Experimental. 13.ed. São Paulo: ESALQ. 240p.

RESENDE MDV. 2014. Selegen Reml/Blup - Sistema Estatístico e Seleção Genética Computadorizada - Manual Complementar do Selegen-Reml/Blup. Viçosa: UFV. 17p.

RESENDE MDV. 2007. Matemática e estatística na análise de experimento e no melhoramento genético. Colombo: Embrapa Florestas. 561p.

SEUFERT P. 2012. The Human Rights Impacts of Tree Plantations in Niassa Province, Mozambique. Heidelberg: FIAN International. 44p.

SHIMANIKIRE T. 2011. Soil Assessment Report for areas Earmarked for Eucalyptus Production (2011/12) Lichinga 1201 (Blocks A, B, C, E, F, G and O) and Massangulo - 2101 (Blocks J and L). Lichinga: Planning Department. 20p.

SHIMIZU JY. 2006. Pesquisa e desenvolvimento florestal em Moçambique. Colombo: Embrapa. 33p. (Documentos 131).

SILVA JM et al. 2011. Variação Genética e ganho esperado na seleção de progênies de Pinus caribaea var. caribaea em Selvíria, MS. Scientia Forestalis 39: 241-252.

VAN ZONNEVELD $M$ et al. 2009. Climate change impact predictions on Pinus patula and Pinus tecunumanii populations in Mexico and Central America. Forest Ecology and Management 257: 1566-1576.

VIEIRA H \& SHIMIZU JY. 1998. Avaliacão do potencial de produtividade de madeira de Pinus tecunumanii no sul de Rondônia. Porto Velho: EMBRAPA. 16p. (Boletim de Pesquisa 24).

ZANELLA LB et al. 2018. Micropropagation of Pinus tecunumanii. Ciência Florestal 28: 651-660. 